\title{
Probabilistic Tsunami Hazard Assessment and Damage Estimation of the Built Environment: Application to the Cascadia Subduction Zone and Seaside, Oregon
}

\author{
Daniel T. Cox, (dan.cox@oregonstate.edu), Hyoungsu Park, Mohammed S. Alam, Andre R. Barbosa \\ School of Civil and Construction Engineering, Oregon State University, USA
}

IMPORTANCE

Risk-based damage estimation to the built environment from future tsunamis is fundamental for developing mitigation and evacuation plans. One of the challenging problems in the evaluation of damage from future tsunamis is that the uncertainty from the nature of tsunami itself (e.g Magnitude, Epicenter, Fault slip distributions) and the lack of accumulated sufficient observed data for probabilistic studies due to the relatively small frquency of tsunami historical events. Even though tsunami modeling has matured over the past several decades and provides reliable estimation of tsunami hazards such as flow depth, velocity, arrival time, etc., questions remain on how to predict future tsunami hazards and how to estimate tsunami damage, especially for the engineers who want to design shelter-in-plate options or coastal planners who want to estimate the possible damage from future tsunami events on the built environment at community and regional scales. As a case study, we evaluate the probabilistic damage states of an urban coastal city, Seaside, Oregon from future tsunamis generated on the Cascadia Subduction Zone (CSZ). The methodology and the results are separated into two parts: (1) Probabilistic tsunami hazard assessment (Park et al., 2017) and (2) Probabilistic building damage assessment from the tsunamis hazards with a community scale.

\section{PROBABILISTIC TSUNAMI HAZARD AND DAMAGE} ANALYSIS

To analyze future tsunami hazards at Seaside Oregon, we consider various slip distributions on the CSZ full-rupture area, which is approximately $1,000 \mathrm{~km}$ from Northern Vancouver Island to Northern California (Fig. 1a). Historically, 19 full-rupture earthquake events were recorded on turbidite data at CSZ with magnitudes ranging from Mw 8.7 to 9.2. The study of inversion models for other subduction zone events has matured enough to provide the reliable slip distributions of past mega-thrust events (2004 India Ocean Tsunami, 2010 Chile Tsunami or 2011 Tohoku Tsunami), and their results allow us to use a Gaussian shape function to describe the shape of the slip distribution along a strike direction. Based on the assumptions that the next significant tsunami at CSZ will occur with full-rupture, we set up total 72 scenarios for future tsunami events which compose of 3 slip distributions per magnitude (Mw. 8.8, 9.0, 9.2) with 8 potential maximum slip locations (Fig. 1b) and numerically analyze all scenarios using the ComMIT (MOST) and COULWAVE model. The weight factor per scenario is determined by turbidities data and expert judgement (Fig. 1c). The tsunami hazard is characterized in term of five intensity measures: (1) maximum flow depth, (2) velocity, (3) momentum flux, (4) the first arrival time $1 \mathrm{~m}$ flow depth, and (5) the duration time over $1 \mathrm{~m}$ flow depth (Fig. 1d). Each intensity damage is utilized to evaluate life safety and damage states of various built-environments, such as buildings, bridges, lifelines of power, water, or telecommunication. In this study, the maximum momentum flux is applied to evaluate the building damage.

FRAGILITY ANALYSIS

After 2011 Tohoku tsunami, surveyed building data have been used to develop various fragility curves accounting for building state, material, floor level, locations, and etc. (Suppasri, et al., 2013). However, these fragility curves only rely on the maximum flow depth that is measurable during post-event field surveys, but it is not directly correlated with tsunami forces, and therefore a weak predictor of building damage. Instead, the momentum flux that is directly related with the hydrodynamic force is utilized in this study. We use the momentum flux fragility curves developed in the Tsunami Methodology Technical Method (2013), which provide various fragility curve for each building type, number of floors, seismic code design level, and various damage states (Fig. 2b). Using three sources of building information such as tax lot data, field survey, and pictures from Google maps, we classify each building type and matched information from individual tax lots to available fragility curves, building types, number of floor levels, and seismic design code level (Fig. 2a). Finally, we evaluate the risk of the building portfolio of the community in Seaside, Oregon to future full rupture CSZ events.

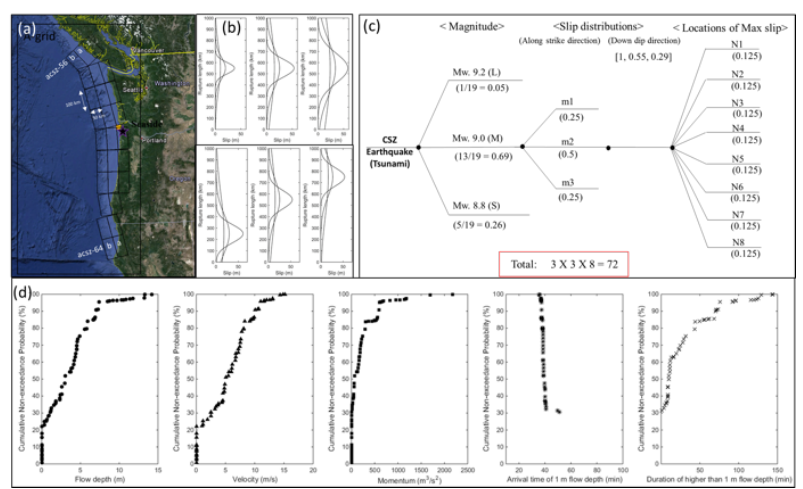

Fig 1: (a) Cascadia Subduction Zone (CSZ), (b) Examples of various slip distributions assumed (c) Logic tree for full rupture CSZ tsunamis events, (d) CDF of different intensity measures.

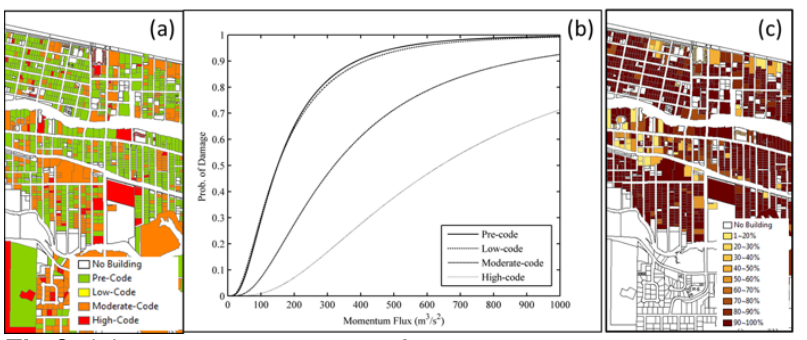

Fig 2: (a) Detail building classification due to seismic code; (b) Example of fragility curves; (c) Example of building damage estimation at Seaside, OR (Complete damage).

\section{REFERENCES:}

Park, H., Cox, D.T., Alam, M.S., Barbosa, A.R., (2017) "Probabilistic seismic and tsunami hazard analysis (PSTHA) conditioned on a mega-thrust rupture of the Cascadia Subduction Zone," Frontiers in the Built Environment, 3, 32.

Suppasri, et al., 2013. "Building damage characteristics based on surveyed data and fragility curves of the 2011 Great East Japan tsunami." Nat Hazards, 319-341. 